\section{Estudo \\ cobebate}

em Cestão

Planejamento
Revista Estudo \& Debate, Lajeado, v. 23, n. 2, 2016. ISSN 1983-036X DOI: http://dx.doi.org/10.22410/issn.1983-036X.v23i2a2016.1072

\title{
O COLEGIADO DO TERRITÓRIO RURAL - CODETER COMO UMA INSTÂNCIA DE ARTICULAÇÃO PARA A PROMOÇÃO DO DESENVOLVIMENTO RURAL NO VALE DO TAQUARI/RS
}

\author{
Cíntia Agostini ${ }^{1}$
}

\begin{abstract}
Resumo: $\mathrm{O}$ desenvolvimento rural é um conceito em construçáo, resultado do avanço nas discussóes para o e no meio rural. Particularmente na agricultura familiar, as açôes de forma cooperada e a participação são percebidas como suas viabilizadoras. Nessas condiçóes, a formação dos Colegiados dos Territórios de Desenvolvimento Rural - Codeters no Brasil considera relevante a formação particular de cada território e a gestão participativa. No caso do Vale do Taquari/RS, o Codeter, formado em 2011, construiu seu Pré-plano de Desenvolvimento Territorial Rural. O objetivo do presente artigo, destacadas as dimensóes histórica, territorial e da participação, é identificar se esse Colegiado é uma instância de articulaçáo do desenvolvimento rural. Para possibilitar o atendimento do objetivo proposto, metodologicamente esta é uma pesquisa qualitativa, que coletou dados documentais e bibliográficos e os tratou a partir da análise de conteúdo.
\end{abstract}

Palavras-chave: Codeter. Desenvolvimento Rural. Vale do Taquari.

JEL: P32, R13, R58

\section{THE COUNCIL OF THE RURAL TERRITORY - CODETER AS A PLACE OF ARTICULATION FOR THE PROMOTION OF RURAL DEVELOPMENT IN THE TAQUARY VALLEY/RS}

\begin{abstract}
Rural development is a concept under construction, as a result of the advances in the discussions for and in the rural area. Especially in family farming, cooperative actions, and participation are seen as their enablers. In these conditions, the formation of Councils of Territories of Rural Development - Codeters in Brazil sees the importance of the particular territorial formation and participative management. In de case of the Taquari Valley - RS, Codeter, created in 2011, built its Pre-Plan to the Rural Territorial Development. The aim of this article, which highlights the historical, territorial and participative dimensions, intends to identify if this Council is a place to articulate rural development. To make it possible to meet the proposed objective, a qualitative research was carried out that selected documentary and bibliographical data, and was seen from a content analysis.
\end{abstract}

Keywords: Codeter. Rural Development. Taquari Valley.

1 Economista, Mestre em Ambiente e Desenvolvimento e Doutoranda em Desenvolvimento Regional. Professora da UNIVATES. 


\section{INTRODUÇÁO}

O desenvolvimento rural, enquanto conceito, constrói-se historicamente e, enquanto prática, se consolida nas últimas décadas. Esse processo promove e possibilita avançar as discussóes que distinguem e fragmentam espaços geográficos para aquelas que compreendem as dinâmicas a partir da formação particular de cada território.

Os Colegiados dos Territórios de Desenvolvimento Rural - Codeters no Brasil são uma tentativa de perceber as particularidades e a participação como aspectos relevantes para o desenvolvimento. Na regiáo aqui estudada, o Vale do Taquari - RS, o Codeter, criado em 2011, ainda está por ser consolidado e é avaliado, a partir de suas proposiçóes iniciais, como uma possível instância de articulação regional para a promoção do desenvolvimento rural.

Para tanto, este texto, em seu primeiro item, destaca a construçáo teórico-histórica do conceito de desenvolvimento rural e da agricultura familiar. Na sequência discorre sobre o Programa de Desenvolvimento Sustentável dos Territórios Rurais - Pronat e a formaçáo dos Colegiados dos Territórios Rurais - Codeters.

Para analisar o desenvolvimento rural do Vale do Taquari e a possibilidade de o Codeter desta região ser uma instância de articulação, este artigo trata da formação histórica regional, destacando aspectos da agricultura familiar e das características associativas.

No item seguinte enfatiza a formação do Codeter Vale do Taquari e a discussão, formatação e ação do Pré-plano de Desenvolvimento Territorial Rural. Traz os aspectos da construção do plano, do envolvimento dos atores, da participaçáo em si, a metodologia proposta e os temas relevantes ao território.

Finaliza destacando as dimensôes histórica, territorial e da participaçáo, que possibilitam que o Codeter Vale do Taquari possa se consolidar como uma instância de articulação do desenvolvimento rural na região.

\section{A FORMAÇÃO TEÓRICO-HISTÓRICA DO DESENVOLVMENTO RURAL E DA AGRICULTURA FAMILIAR}

O presente artigo não se remete a períodos históricos do desenvolvimento rural, mas faz uma pequena leitura dos anos de 1950 em diante. As discussóes acerca da agricultura, do setor agrícola, coincidem com a fase de crescimento da economia mundial pós Segunda Guerra. É um período conhecido na literatura econômica como os anos dourados do capitalismo, caracterizado pela consolidação da economia americana, recuperação das economias envolvidas com a guerra e as disputas dos países capitalistas e socialistas, via Guerra Fria. Ele também é entendido como o momento quando os Estados Nacionais criaram os sistemas de proteção social, o que em alguns países e na literatura em geral ficou conhecido como welfare state e que em outras sociedades foi o modelo perseguido, mas não alcançado (PEREIRA; SILVA; PATRIOTA, 2006).

Os países vinculados ao sistema capitalista de produção empreenderam, neste período, esforços para incluir a sociedade e aumentar a "capacidade de consumo das famílias dos trabalhadores" (MEDEIROS, 2001, p. 7), o que repercute no aumento da demanda do setor privado e de gastos no setor público. 
As áreas rurais, nesse contexto, eram vistas como apartadas pelas áreas urbanas. As grandes fazendas eram produtivas e mecanizadas e as pequenas propriedades possuíam papel passivo nas economias nacionais e mesmo nas locais. A indústria crescia vinculada ao cenário destacado acima, e a agricultura servia para aportar alimentos às áreas urbanizadas (ELLIS; BIGGS, 2001).

Nos anos de 1960 seguem as mesmas condições da economia mundial, aprofundase a mecanização agrícola; e a Revolução Verde nasce e se consolida nos anos de 1970. A Revolução Verde está associada à lógica produtiva global, "materializou-se de fato sob um padrão tecnológico, o qual, onde foi implantado de forma significativa, rompeu radicalmente com o passado por integrar fortemente as famílias rurais a novas formas de racionalidade produtiva" (NAVARRO, 2001, p. 84).

O período de ouro do capitalismo se rompe nos anos de 1970, pelas crises advindas dos choques do petróleo, aumento dos juros internacionais, dívidas dos países latinoamericanos e a formação de blocos econômicos em contraposição à hegemonia americana. Mantém por mais um curto período o dualismo entre socialismo e capitalismo. Os países latinos passam o período entre os anos de 1970 e 1980 atrelados politicamente a golpes militares e economicamente voltados para tratar de seus problemas inflacionários (FIORI, 1997).

Nesse mesmo período, no contexto internacional, emerge o processo de globalização e financeirização da riqueza, em contraposiçâo às políticas keynesianas que prevaleciam até então, fazendo com que os países tenham que se adaptar, das mais distintas formas, a essa lógica global internacional. Para Fiori, "globalização é um fato, mas só é global do ponto de vista das finanças que passaram a operar num 'espaço mundial' hierarquizado a partir do sistema financeiro norte-americano e viabilizado pela política econômica do estado hegemônico, imitada, de imediato, pelos demais países industrializados" (FIORI, 1997, p. 90).

Já no âmbito do desenvolvimento rural, avança-se de uma visão "from the topdown or 'blueprint' approach to rural development, characterized by external technologies and national-level policies, to the bottom-up, grassroots, or "process' approach" (ELLIS; BIGGS, 2001, p. 443). Esta nova percepção do desenvolvimento rural permite a promoção de processos participativos, a capacitação dos atores para assumirem o controle e determinar as prioridades nas áreas rurais.

Instituiçóes internacionais, organismos de fomento, compreendem melhor que as açóes, políticas e programas devem levar em conta as diversas dimensóes, desde perspectivas dos atores, condiçóes sociais, a atuação do Estado, o mercado privado, entre tantos outros, para entấo promover o desenvolvimento rural. Já não é mais suficiente a percepção competitiva da propriedade, em que aquelas produtivas levaráo positivamente toda a

2 "De cima para baixo ou de modelos para o desenvolvimento rural, que se caracteriza por tecnologias externas e políticas em nível nacional, para perspectivas de baixo para cima ou abordagem de processo" (Traduzido pelo autor). 
economia ao desenvolvimento, desconsiderando as pequenas propriedades, a produção de subsistência e o conhecimento adquirido ao longo da história.

A partir dos anos de 1980, e em 1990 no caso dos países latinos, o mundo "enquadrase" nas condiçóes do neoliberalismo, quando o papel do Estado é enfraquecido e "igualmente retirariam o desenvolvimento rural da cena de discussóes" (NAVARRO, 2001, p. 85).

Durante a própria década de 1990 , as naçóes percebem que o movimento benéfico do crescimento e da globalização, do Estado mínimo e neoliberalismo, não possibilitam certamente o desenvolvimento das naçóes, principalmente se consideradas as questóes da concentração de renda, aumento da pobreza e diferenças sociais (FIORI, 1997).

Ainda, movimentos sociais surgem e consolidam-se, alguns como tentativa de reaçáo e outros na busca pela consolidaçáo do sistema capitalista globalizado. No caso do Brasil, a própria Constituição de 1988 e a saída do Golpe Militar possibilita a origem das instituiçóes participativas (SCHEREN-WARREN; LÜCHMANN, 2004; AVRITZER, 2009).

Durante o avançar da segunda metade do século XX, aqui brevemente explicitada, o desenvolvimento passa de agrícola para agrário e, por fim, rural (NAVARRO, 2001). Desenvolvimento rural é entendido como aquele que

[...] deve combinar o aspecto econômico (aumento do nível e estabilidade da renda familiar) e o aspecto social (obtenção de um nível de vida socialmente aceitável), e que sua trajetória principal possa residir na diversificação das atividades que geram renda (pluriatividade) (KAGEYAMA, 2004, p. 388).

Ou, ainda, "pode se referir também à elaboraçâo de uma 'ação prática' para o futuro, qual seja, implantar uma estratégia de desenvolvimento rural, para um período vindouro" (NAVARRO, 2001, p. 88). Para tanto, metodologias, programas, estratégias e açóes são necessários para o alcance de tal ação prática, principalmente a partir da relação dos atores no processo.

Independente da corrente teórica que discute o tema do desenvolvimento rural, "há um relativo consenso sobre a dimensão multidimensional da sustentabilidade do desenvolvimento, assim como em relação ao papel da agricultura familiar e das formas heterogêneas de sua inserção na dinâmica da economia capitalista" (SCHNEIDER, 2010, p. 528).

E, nessas condições, o desenvolvimento rural também assume o adjetivo sustentável, muito mais para reforçar as perspectivas ambientais nesse contexto do que efetivamente para agregar algum aspecto até então desconhecido na dinâmica rural. Ou seja, associar aspectos econômicos, sociais e ambientais no âmbito do desenvolvimento é um possível desenvolvimento rural sustentável.

Esse conceito náo é, no entanto, consenso nem mesmo as práticas são uniformes ou modeladas, mas, se tratado como resultado de ações concretas de baixo para cima, ou bottom-up, faz sentido associar a perspectiva aqui proposta. Ou seja, considerar esse conceito de desenvolvimento rural, apesar de haver tantas outras percepçôes, é levar em conta a lógica territorial do desenvolvimento, em que "um território só existe a partir da materialidade que lhe é dada pelo seu uso" (ETGES, 2005, p. 54). 
A discussão sobre a definição de rural é praticamente inesgotável, mas parece haver um certo consenso sobre os seguintes pontos: a) rural não é sinônimo de agrícola e nem tem exclusividade sobre este; b) o rural é multissetorial (pluriatividade) e multifuncional (funçóes produtiva, ambiental, ecológica, social); c) as áreas rurais têm densidade populacional relativamente baixa; d) não há um isolamento absoluto entre os espaços rurais e as áreas urbanas. Redes mercantis, sociais e institucionais se estabelecem entre o rural e as cidades e vilas adjacentes (KAGEYAMA, 2004, p. 382).

Os diversos conceitos e dimensóes do desenvolvimento rural são discutidos por Ellis e Biggs (2001), Navarro (2001), Kageyama (2004), Buainain, Romeiro e Guanziroli (2003) e Schneider (2004; 2010). Não é foco do presente artigo discutir os diversos conceitos e concepçóes de desenvolvimento rural; no entanto, é aceito que um conjunto de fatores são elementos fundantes dele: a integraçấo entre a zona rural e urbana, percebendo que não existe mais a distinção que antes parecia explícita entre o meio urbano e o meio rural; as influências dos processos de industrialização, do empreendedorismo e a urbanização que se consolidaram ao longo do tempo; a pluriatividade e a multifuncionalidade das propriedades rurais; os aspectos que possibilitam vantagens comparativas a diversos locais e/ou regióes; e os programas gerais de geração de emprego e renda, melhoria de vida e combate à pobreza, implantados pelos Estados nestas últimas décadas (KAGEYAMA, 2004).

Além de explicitar o conceito de desenvolvimento rural admitido neste texto, faz-se necessário salientar que existem diferentes formas de agricultura e que interagem de modo diverso com o desenvolvimento rural (CONTERATO; SCHNEIDER; WAQUIL, 2010).

Não cabe aqui, no entanto, tratar das diversas formas de propriedade como o agronegócio e as propriedades camponesas. Tão somente é tema e são destacados os termos que particularizam a agricultura familiar.

[...] a agricultura familiar também abrange a produção agrícola familiar, mas não se restringe a ela, da mesma forma que o desenvolvimento rural compreende formas de agricultura exclusivamente agrícolas, mas não se restringindo a elas. Pretende-se avançar no debate acerca do reconhecimento da agricultura familiar enquanto uma estratégia de desenvolvimento rural, vinculando as atividades agrícolas e não agrícolas às dinâmicas locais e territoriais de desenvolvimento e à sua capacidade de gerar e potencializar endogenamente a base de recursos através da qual a agricultura se reproduz. Isso implica o reconhecimento de formatos agrícolas mais autônomos ou mais dependentes no que tange à capacidade de co-produção e manejo dos recursos disponíveis, aspectos fundamentais na determinaçáo do grau de autonomia das unidades produtivas (CONTERATO; SCHNEIDER; WAQUIL, 2010, p.151-152).

Essa opção se dá pois no Vale do Taquari, território analisado neste artigo, são as propriedades vinculadas à agricultura familiar que preponderam. A média de tamanho das propriedades é de 13,4 hectares, 79\% delas são de proprietários integrais, ou seja, dedicamse à propriedade integralmente, e 79,5\% delas utilizam mão de obra familiar. Em 2005, $48,1 \%$ dos proprietários eram associados a cooperativas e $82 \%$ da economia dessa regiấo dependem direta e indiretamente da produção do agronegócio, que processa e agrega valor ao cultivado pela agricultura familiar (FETAG; UNIVATES, 2005). 
A partir da perspectiva aqui exposta, um dos aspectos relevantes na discussão do desenvolvimento rural, principalmente no final do século XX e início deste, é a participação social, isto é, a atuação dos atores nas dinâmicas bottom-up.

Não há consenso de que seja positiva ou negativa, nem de que essa seja uma relação dual, muito menos que as instituiçóes, os atores, estejam qualificados ou imbuídos de princípios somente coletivos e democráticos. Ou seja, o que se quer afirmar é que a construçáo social do desenvolvimento rural náo é tão uniforme e positiva, mas que atualmente tem sido destacada como alternativa às práticas e teorias anteriores, quando as decisóes, estratégias e açóes eram determinadas de forma top-down, de cima para baixo.

Atrelada a essa perspectiva, na tentativa de explicitar a participação e a organização social, conforma-se aquilo que fica reconhecido como sociedade civil. "O crescimento das formas de organização da sociedade civil no Brasil foi um dos elementos mais importantes da democratização do país" (AVRITZER, 2009, p. 29), marcadamente no processo da Constituinte.

$\mathrm{O}$ referido conceito surge na tentativa de descompatibilizar a relação dual entre Estado e sociedade. O termo sociedade civil é um dos mais utilizados atualmente, no senso comum, meio acadêmico, nas práticas de gestão e mobilização, no entanto é um conceito diverso e até contraditório ${ }^{3}$.

\begin{abstract}
No seu conjunto, a ampliação e a pluralização das ONGs, a criaçáo (e generalizaçáo) dos espaços de participação social na gestão de políticas públicas e a incorporação de um conceito de espaço público diferenciado do Estado se constituíram, entre outros, em motivo importante para a renovaçáo - que alguns interpretaram como 'crise' - das análises no campo dos movimentos sociais. Conceitos como sociedade civil, capital social e democracia participativa passaram a assumir um lugar de destaque na produção das Ciências Sociais, indicando novos contextos político-sociais e novas preocupaçóes teóricoconceituais (SCHEREN-WARREN; LÜCHMANN, 2004, p.19).
\end{abstract}

O aspecto da participação social e das representações via entidades organizadas é ainda mais saliente quando as pequenas propriedades agrícolas coexistem umas em função das outras. Considerando a lógica atual do capitalismo, as grandes propriedades inserem-se no contexto global de forma mais competitiva (FIORI, 1997), enquanto as propriedades da agricultura familiar não possuem as mesmas condiçóes de atuarem, se manterem produtivas e gerando renda e empregos. Nessas condiçóes, a participação social e a relação dos atores tornam-se pertinentes e, em alguns momentos, significativas.

3 Não são tema deste artigo, mas as discussões acerca do tema da sociedade civil possuem, ao menos, quatro concepçôes particulares, a partir de matrizes diversas, em que o conceito de sociedade civil é adequado em diferentes construçôes teóricas, a matriz neoliberal, a matriz neotocquevilliana, a matriz neogramsciana e a matriz habermasiana (RAMOS, 2005; FRANCO, 2007; DURIGUETTO, 2008; DURANTE; SANDES, 2009). Mesmo estas sofrem críticas e construçôes mais atuais discutem os conceitos de sociedade civil considerando que esta é privada, sugerem estudos empíricos, concretos, sem conceito idealizado de sociedade civil e movimentos sociais, valorizam a heterogeneidade e buscam analisar quais são os limites e possibilidades nos diversos espaços políticos (LAVALLE, 2003; 2011; HOUTZAGER, LAVALLE; ACHARYA, 2004). 
Ainda, este é tema fundamental na formação dos Codeters no Brasil. A Secretaria de Desenvolvimento Territorial - SDT, vinculada ao Ministério de Desenvolvimento Agrário - MDA, deixa claro que sua Missão é "Apoiar a organização e o fortalecimento institucional dos atores sociais locais na gestão participativa do desenvolvimento sustentável dos Territórios da Cidadania e Rurais e promover a implementação e a integração de políticas públicas" (MDA, 2015, s.p.).

Percebem-se claros termos que indicam a intenção de estimular a participação quando a missão cita atores sociais locais, aqui também identificados regionais, e a gestão participativa.

Nessas condiçóes, os Codeters devem levar em conta que a construção social se dá a partir das práticas sociais de cada território, que dependem de cada comunidade, de como esta interage entre si e com os outros, inclusive outras escalas.

A abordagem territorial assume a função de uma ferramenta para se pensar o planejamento e a intervenção no tecido social. [...]. Neste caso, o território passa a ser uma unidade de referência, um nível de operação e agregação adequado para operar o planejamento de açóes governamentais e políticas públicas que promovam mudanças e transformaçôes múltiplas no tecido social (SCHNEIDER, 2004, p. 110).

Dessa forma, diferentes e diversas correntes teóricas discutem o tema da participação social, explicitada de forma geral. Alguns tratam do tema a partir da formação do capital social, cujo principal autor é Robert Putnam (1996). Outros contemplam o tema do desenvolvimento rural a partir da perspectiva orientada aos atores, cujos principais autores são Norman Long e Jan Douwe van der Ploeg (2011). Outros o abordam a partir da Teoria do Ator Rede, baseada nas discussóes de Bruno Latour (2012), entre outros. Diferentes autores propóem discussóes a partir da perspectiva da mediação social de Olivier de Sardan (1995). Um grupo trata dos mesmos temas a partir da lógica da reciprocidade, cujo precursor é Eric Sabourin (2011). Alguns ainda trabalham com a perspectiva da autonomia e resistência de James Scott (2011). E, por fim, mas não por último, um grupo de autores discute o tema do desenvolvimento rural a partir do embeddedness, enraizamento, discutida por Mark Granovetter (1985).

Além dessas, existem diversas outras correntes de pensamento. O cuidado na discussão dos diversos temas é não assumir preconcepçóes distintas ou tratar a partir de conceitos diversos, e até mesmo contrários. No entanto, não cabe aqui discutir as diversas e diferentes percepções de compreender a participação, a relação entre os atores e a gestão dos projetos de desenvolvimento rural sob uma ou outra perspectiva teórica. Todas sofrem críticas, amadurecem à medida que são trabalhadas e são visões parciais da complexa realidade.

Foley e Edwards (1998), Lavalle (2003; 2011), Dagnino (2004), Dagnino, Olvera e Panfichi (2006) e Houtzager, Lavalle e Acharya (2004) criticam as discussóes a partir das percepçóes da sociedade civil. Percebem que nem a sociedade civil é homogênea nem os atores são democráticos, identificando muito mais um contínuo da sociedade civil, Estado e mercado, do que lógicas específicas de esferas individuais. 
Mas o que se pode perceber é que, na maioria das discussóes atuais, perpassam interpretaçôes de que é necessário compreender quem são os atores empiricamente, como constroem as suas visóes, suas perspectivas; considerar que possuem limites e são diversos. Não obstante, a participação não é percebida somente a partir de movimentos sociais formais ou informais, das minorias, para combater algo, para insurgir sobre um sistema dito dominante, mas também participaçóes nas "quais atores sociais, ainda que em posiçóes opostas, adotam horizontes estratégicos comuns em torno de projetos compartilhados" (ABRAMOVAY, 2010, p. 272).

Essas correntes teóricas criticam a sociedade idealizada, em que as associaçóes são a representação de uma visão normativa, os indivíduos são virtuosos e iguais, e em momento algum colocam interesses particulares acima de interesses coletivos. Discutem as percepçôes que excluem grupos e organizaçóes que assumem um caráter conflitivo, privilegiando aquelas organizaçóes que produzem atitudes e comportamentos de virtude cívica, dando ênfase ao caráter normativo da sociedade civil, na lógica de que esta seria o locus de realização da autêntica solidariedade e confiança mútua.

As perspectivas citadas compreendem que existe diversidade social no território, ou seja, este não é homogêneo, e que essas particularidades devem ser percebidas e analisadas como constantes transformaçóes do espaço construído.

O território é um espaço construído e particular, conforme já explicitado, e

[...] o desafio maior é delinear os contornos e conteúdos de formas sociais diversas, explicando sua gênese e traçando suas implicações para a ação estratégica e modos de consciência. É necessário entender como estas formas tomam contorno sob condiçóes específicas e em relação a configuraçóes passadas (DEPONTI, 2006, p. 8-9).

Ou seja, mesmo tendo clareza do contexto citado acima, é por meio dos sistemas de participação que é mais perceptível a emergência de características sociais que perpassam o compromisso com o coletivo, as regras de reciprocidade e a confiabilidade uns nos outros e nos sistemas. Compromisso coletivo considerado nos grupos e com os diferentes grupos, é presente quando da discussão do desenvolvimento rural, na busca de identidade em um determinado território. Regras de reciprocidade consideradas no olhar a partir do outro, na percepção e açôes coletivas ou individuais positivas e que gerem reaçóes de igual forma no ato e fato de colocar-se no lugar do outro e a confiabilidade para dar conta de levar adiante as ações coletivas de forma recíproca.

Tal participação cidadã contribui para solidificar as identidades e surge da interação sócio-político-econômica, na qual os indivíduos, apesar de suas diferenças, possibilitam a identificação e o trabalho por interesses comuns. Nessas condições, as iniciativas deixam de ser tomadas por outros, que nem sempre são efetivas, e passam a ser das instituiçóes, organizações, indivíduos de cada território.

Neste processo de gestão, focalizado sob a abordagem territorial, o MDA prevê a necessária articulaçáo social (em rede) entre os diversos agentes (públicos e privados), a descentralização das decisões e a constituição de institucionalidades de compartilhamento de responsabilidades e poder. Sob esse olhar se focaliza a participação dos atores sociais em 
todas as etapas que vão desde as mobilizaçôes até o acompanhamento e controle das ações elaboradas e acordadas mutuamente sobre as necessidades da região (FREITAS; FREITAS; DIAS, 2012, p.87).

E é essa a perspectiva implícita no Programa de Desenvolvimento Sustentável dos Territórios Rurais - Pronat, que institui os Colegiados dos Territórios Rurais - Codeters. Para tratar dessa afirmaçấo e dar continuidade na análise proposta, na sequência traz-se o Programa Nacional, a formação dos Codeters e, por fim, o histórico e a formação do Codeter do Vale do Taquari.

\section{O PROGRAMA DE DESENVOLVIMENTO SUSTENTÁVEL E A FORMAÇÃO DOS COLEGIADOS DOS TERRITÓRIOS RURAIS DO MINISTÉRIO DO DESENVOLVIMENTO AGRÁRIO}

Vinculada ao Ministério do Desenvolvimento Agrário do Brasil - MDA está a Secretaria de Desenvolvimento Territorial - SDT. "A SDT tem como estratégia de ação de atuação a abordagem territorial do desenvolvimento expressa no Programa de Desenvolvimento Sustentável de Territórios Rurais" (MDA, 2015, s.p.).

Com efeito, o Programa de Desenvolvimento Sustentável dos Territórios Rurais (Pronat), também conhecido como Territórios Rurais de Identidade, está no cerne da formação da própria SDT, ocorrida em 2003, durante o início do primeiro governo Lula. Este programa passou a operar de forma regulamentada em julho de 2005, quando obteve sua chancela formal por intermédio da Portaria oํ 5, de 18/07/2005 (DELGADO; LEITE, 2011, p. 432).

As diretrizes da Secretaria e dos Programas vinculados ao desenvolvimento sustentável dos territórios rurais adotam "a abordagem territorial como referência conceitual para a promoção do Desenvolvimento Rural Sustentável” (MDA, 2015, s.p.) e percebem "o território como espaço socialmente construído, lugar de manifestação de diversidades culturais e ambientais que expressam limites e potenciais para a promoção do desenvolvimento rural sustentável” (MDA, 2015, s.p.).

O Ministério enfatiza ainda que o desenvolvimento dos territórios deve articular as dimensōes socioculturais, político-institucionais, econômica e ambiental. Ele valoriza a participação dos atores sociais em todo processo de construçáo do desenvolvimento dos territórios rurais, inclusive incentivando a adoção de metodologias participativas, articulaçóes multiníveis de políticas públicas e adoção de formas de descentralização da gestão dos territórios (MDA, 2015).

O alcance do desenvolvimento territorial depende, além de fatores externos ao controle das açóes e iniciativas da SDT e seus parceiros diretos, de um conjunto de ações que incidem sobre eixos centrais de intervenção, por intermédio, elaboraçấo, implementação e gestão do Plano Territorial de Desenvolvimento Rural Sustentável - PTDRS, e da implantação do conjunto de projetos a ele vinculados (MDA, 2015, s.p.). 
O Pronat considera os Territórios Rurais como espaços de articulação e gestão de políticas públicas. Trata-se de uma ação de Estado dirigida para regiôes rurais nas quais espera-se (sic) que foram construídas relaçóes de pertencimento e identidades culturais e geográficas (VILPOUX; LAURINO; CAMPEÁO, 2014, p. 44).

Para a SDT, a abordagem territorial é fundante, pois não é possível resumir o rural ao agrícola, ou seja, utilizam-se os conceitos de desenvolvimento rural situados nesse artigo. A Secretaria enfatiza que a escala municipal é muito restrita para o planejamento, gestáo e promoção do desenvolvimento sustentável dos territórios e destaca a necessidade de descentralizar as políticas públicas. Em suma, ressalta diversas escalas e múltiplas dimensões para uma percepção sistêmica do território (DELGADO; LEITE, 2011).

Assim sendo, existe a clara percepção de que a regiáo é resultado de formação particular de cada território, enquanto relação entre sociedade e ambiente, sociedade e natureza. Território como o espaço de construção das regióes, em seus arranjos territoriais particulares, assim, tal é resultado da

[...] apropriaçáo do espaço pela ação social de diferentes atores. [...] o conceito de território incorpora o jogo de poder entre os atores que atuam num espaço. Como resultado desse jogo de poder, se define uma identidade relacionada a limites geográficos, ou ao espaço determinado (FLORES, 2006, p.4).

Considerando que o território é resultado da ação dos atores, existem diversas formas de fortalecer o espaço construído (SANTOS, 1996) e promover o desenvolvimento rural. Se levado em conta que é a partir das particularidades, sendo estas culturais, sociais, ambientais, políticas, econômicas, há uma decisão do próprio território em como promover o desenvolvimento.

Durante o desenvolvimento do Programa, o Governo Federal percebeu que algumas regióes necessitavam de maior atenção. A partir dessa perspectiva, diferencia os Territórios da Cidadania, Programa lançado no ano de 2008. Os regramentos são os mesmos dos Rurais. Conforme Delgado e Leite (2011, p. 434), "a prioridade era atender territórios que apresentassem baixo acesso a serviços básicos, índices de estagnação na geração de renda e carência de políticas integradas e sustentáveis para autonomia econômica de médio prazo".

Diferentemente de outros Programas e projetos, os Codeters e Territórios da Cidadania avançam na perspectiva dos programas federais, para, além das decisóes técnicas e implantação nos locais, um processo de participação e gestão social. Participação não somente do setor público, representantes envolvidos diretamente, mas uma composição paritária das mais diversas entidades, representaçóes, setor público, sociedade civil organizada e atores do desenvolvimento rural.

A política de desenvolvimento territorial no meio rural representou um avanço considerável, isto é, uma inovação institucional, ao implementar um formato mais adequado à ampliação da capacidade de participação social dos atores no processo de diálogo, negociação, desenho e planejamento de políticas públicas, incrementando aquilo que poderíamos denominar como um dos atributos da capacidade governativa e da gestáo social dos processos de desenvolvimento (DELGADO; LEITE, 2011, p. 463-464). 
Após perceber que a atuação da SDT e a formação dos Codeters leva em conta o desenvolvimento rural proposto neste artigo, que é relevante à formação particular de cada território e à gestão participativa, o artigo destaca os procedimentos metodológicos utilizados neste trabalho para expor, na sequência, a formação do Codeter no Vale do Taquari.

\section{PROCEDIMENTOS METODOLÓGICOS}

Metodologicamente, este estudo trata-se de uma pesquisa qualitativa, considerando que esta abordagem busca "compreender os sistemas de significados utilizados por um grupo ou uma sociedade" (BAQUERO et al., 1995, p. 21).

Nesse contexto, o artigo busca compreender como as diversas dimensóes possibilitam que o Codeter contribua na articulaçáo do desenvolvimento rural no Vale do Taquari.

Relevante salientar que, considerando o procedimento de coleta de dados, foi necessário "descrever a situação do contexto em que está sendo feita determinada investigação" (GIL, 1999, p. 73). Como situação contexto destacam-se as particularidades regionais e, mais precisamente, o território onde o estudo está sendo proposto. A regiáo de abrangência da presente pesquisa é o Vale do Taquari.

Já a coleta de dados se deu a partir de dados bibliográficos e documentais. Enquanto pesquisa bibliográfica, "na atualidade, praticamente qualquer necessidade humana, conhecida ou pressentida, tem algo escrito a seu respeito. Por isso, a pesquisa com base em uma bibliografia deve encabeçar qualquer processo de busca científica que se inicie" (SANTOS, 2007, p. 30). Considera-se essencial a pesquisa bibliográfica "à construção do objeto de pesquisa e como tal deve ser tratado" (ALVES, 1992, p. 58). Nessas condiçóes foram analisadas referências que deram conta de aprofundar o conhecimento e possibilitaram "o desenvolvimento teórico-metodológico" do artigo (ALVES, 1992, p. 58).

Também foram feitas pesquisas nos documentos do Codeter, mais precisamente o Pré-plano de Desenvolvimento Territorial Rural, citados ao longo do texto. Foi considerado que "documento é o nome genérico dado às fontes de informação bibliográficas que ainda não receberam organização, tratamento analítico e para publicação" (SANTOS, 2007, p.32).

Por fim, o tratamento dos dados foi realizado por meio de análise de conteúdo, pois "é considerada uma técnica para o tratamento de dados que visa identificar o que está sendo dito a respeito de determinado tema" (VERGARA, 2005, p. 15). Todos os dados coletados qualitativamente, sejam eles bibliográficos, documentais, foram avaliados nessas condiçóes.

\section{O CODETER DO VALE DO TAQUARI COMO INSTÂNCIA DE ARTICULAÇÃO PARA A PROMOÇÁO DO DESENVOLVIMENTO RURAL}

O Colegiado do Território Rural do Vale do Taquari está em construçấo. Inicia sua formação em 2011, quando do primeiro encontro, na cidade de Cruzeiro do Sul, e, a partir desse momento, desencadeia um diálogo regional para formatar o Plano Territorial e a adesão das entidades (CODETER, 2014).

Em seu Regimento Interno destaca-se: 
Art. $1^{\circ}-\mathrm{O}$ presente Regimento Interno visa regulamentar as atribuiçôes e funcionamento do Colegiado de Desenvolvimento Territorial (CODETER) do Território do Vale do Taquari/RS, instituído por deliberação unânime dos seus membros, conforme relação anexa, em assembleia ocorrida em 06 de dezembro de 2011. O CODETER promoverá o debate, a articulação e a implementação de açôes de desenvolvimento rural sustentável no território, visando a participação social na formulação, gestão e na integraçáo das políticas públicas, a garantia de direitos sociais, melhoria da renda e da qualidade de vida, especialmente no meio rural, bem como a preservação ambiental, tendo como público prioritário a agricultura familiar, os assentados da reforma agrária e beneficiários do programa de crédito fundiário, pescadores artesanais, quilombolas, pecuaristas familiares, indígenas e assalariados rurais. O CODETER terá caráter permanente, exercendo ação de planejamento e gestáo do Plano Territorial de Desenvolvimento Rural Sustentável PTDRS e de outros planos e projetos com natureza semelhante, assim como em relação aos programas governamentais, exercendo o controle social nos municípios que o compóem (CODETER, 2014, p. 90).

Durante todo o processo de planejamento foram engajadas entidades públicas e privadas, com diferentes olhares locais e regionais, até finalizar a construção do Pré-Plano Territorial de Desenvolvimento Rural do Vale do Taquari.

O Codeter considerou a formação do colegiado e o plano que o sucedeu como o "início de um processo de planejamento regional, que não tenta esgotar, muito antes pelo contrário, tenta dar os primeiros passos em prol do desenvolvimento de uma agricultura sustentável para o Vale do Taquari” (CODETER, 2014, p. 3).

O referido plano contextualiza os aspectos teóricos de desenvolvimento, planejamento e de formação e construção do plano a partir da participação, dando destaque ao capital social. Na sequência, apresenta dados e informaçôes quantitativas dos municípios do Vale do Taquari que contextualiza a regiáo, formatando o diagnóstico situacional. Nos itens seguintes traz a metodologia, cronogramas de trabalho e a definição de microrregióes utilizada pelo Colegiado.

Assim, o documento que conforma o Pré-Plano identifica as Matrizes FOFAs Fortalezas, Oportunidades, Fraquezas e Ameaças, os Eixos Estratégicos e Ações, a Priorização das Ações, os Eixos Prioritários, Programas e Ações e a Definição de Pré-Projetos. Por fim, identifica os grupos de trabalho que teriam incumbência de tratar dos temas prioritários e discutir projetos a serem encaminhados para o MDA.

O diagnóstico levantou dados e informaçōes secundárias que identificam os municípios que compóem o colegiado. A área de abrangência determinada para o território foram os quarenta municípios que compunham a Associação de Municípios do Vale do Taquari - Amvat no período. Essa foi uma decisão colegiada a partir de um território já construído. No entanto, no decorrer do trabalho foram definidas cinco microrregióes, decididas em plenária do Colegiada, que possibilitaram as discussóes em grupos menores de municípios, com características similares (CODETER, 2014).

O fato de serem definidas escalas diversas para o processo de planejamento, municipal, microrregional e regional é relevante, pois busca identificar as particularidades dos territórios e articulá-los regionalmente, no entanto o movimento parece acontecer do município-microrregiâo-região e regiáo-microrregiấo-município, o que nem sempre é 
salutar, já que as escalas podem se articular em distintas dimensões, perspectivas e arranjos (HEROD, 2003).

O diagnóstico ainda apresenta dados socioeconômicos, sempre no âmbito municipal. No entanto, no documento não se percebe que esses dados foram utilizados nas discussóes dos temas prioritários, na construção da matriz FOFA efetivada. Apesar de haver temas coincidentes, não há evidências de que esse processo de vinculação foi intencional.

Quando analisado o processo participativo, ou seja, o engajamento dos diversos atores, suas representaçóes e institucionalidades, percebe-se que participam do Codeter Vale do Taquari representaçóes do setor público e da sociedade civil, conforme determinado nas orientaçôes do Pronat. "O Plenário é órgão colegiado superior, ao qual competem todas as decisóes estratégicas ligadas ao processo de desenvolvimento territorial” (CODETER, 2014, p. 92).

Como membros do setor público são identificadas 30 prefeituras municipais, das 40 que fazem parte do território, o Consórcio Público para Assuntos Estratégicos do G8 Cipae G8, a Fepagro Regional do Vale do Taquari, a Secretaria de Desenvolvimento Rural, Pesca e Cooperativismo - Coordenadoria dos Vales do Taquari e Rio Pardo, a Secretaria de Planejamento, Gestão e Participação Cidadã - Coordenadoria Regional, o Ministério da Agricultura, Pecuária e Abastecimento/Unidade Técnica Regional da Agricultura - MAPA/ UTRA, a Universidade Estadual do Rio Grande do Sul - Uergs Encantado e 12 escritórios da Emater/Ascar da região.

Como representantes da sociedade civil, entidades organizadas juridicamente, cuja paridade com o setor público deve ser igualitária, há representações de 12 Sindicatos de Trabalhadores Rurais de municípios, duas regionais sindicais do Vale do Taquari, a Associação de Desenvolvimento Rural Sustentável de Poço das Antas - Adrspa, a Associação dos Municípios de Turismo do Vale do Taquari - Amturvales, duas Associaçóes de Mulheres (Colinas e Estrela), a Associação Estrelense das Sociedades de Água - Aesa, a Associação dos Feirantes de Estrela - Asfe, a Associação para o Desenvolvimento Rural Estrela - Adere, a Fundação Agrícola Teutônia, a Câmara da Indústria, Comércio e Serviços do Vale do Taquari - CIC Vale do Taquari, o Movimento dos Pequenos Agricultores - MPA, o Centro de Apoio ao Pequeno Agricultor - CAPA, a Faculdade La Salle de Estrela, 12 Conselhos municipais de Agricultura e/ou Desenvolvimento Rural, o Conselho de Desenvolvimento do Vale do Taquari - Codevat, o Sicredi Regiāo dos Vales, a Univates, a Cooperativa Agroindustrial São Jacó - Cooperagri, o Sicredi Ouro Branco e três Cooperativas Regionais, duas de alimentos e uma de eletrificação rural.

Além da composição do Colegiado, o Codeter Vale do Taquari possui um Núcleo Dirigente e um Núcleo Técnico para coordenar as ações do território e representar o Codeter, quando necessário. O Núcleo Técnico é formado por representaçóes que têm por finalidade apoiar tecnicamente a construção do Território Rural do Vale do Taquari.

No Núcleo Dirigente estão, também de forma paritária, setor público e sociedade civil: do setor público participam a Amvat, Regional da Emater/Ascar, Coordenadoria Regional da SDR e Coordenadoria Regional da Seplag; da sociedade civil, a Regional Sindical da Fetag, o MPA, o CAPA, um representante das Cooperativas, um representante 
das Associações, um representante dos Conselhos Municipais e um membro do Núcleo Técnico - atualmente o representante do Codevat é o membro que compóem o Núcleo Dirigente, representando o Núcleo Técnico.

No Núcleo Técnico participam Codevat e Fundação Agrícola Teutônia, representando a sociedade civil, e MAPA/UTRA, Fepagro, Uergs, Emater/Ascar Lajeado, representando o setor púbico.

Para a dinâmica de planejamento do Plano Territorial do Codeter, ocorreram discussóes municipais, nas quais as matrizes FOFAs foram discutidas com representantes da agricultura familiar, das prefeituras, de entidades representativas do setor, da comunidade em geral, sendo questionado: "Qual o desenvolvimento que temos atualmente em relação aos aspectos econômico, social, ambiental e político-institucional?” (CODETER, 2014, p. 47).

Após as discussões municipais sucederam-se etapas microrregionais. A dinâmica para esses encontros foi a sistematização das matrizes criadas nos municípios e posteriormente a discussão de "Qual o Desenvolvimento que queremos?” (CODETER, 2014, p. 48).

Também nessas reunióes microrregionais, os presentes elencaram as potencialidades, desafios, riscos e limitaçóes, utilizando a matriz Swot ou FOFA, e considerando os aspectos econômicos, sociais, ambientais e político-institucionais.

O processo de planejamento seguiu com a sistematização dos trabalhos pelos Núcleos Técnico e Dirigente e, posteriormente, foi apresentado para aprovação da plenária.

Nela os resultados foram demonstrados por microrregião, enfatizando forças, fraquezas, oportunidades e ameaças para os eixos econômico, social, ambiental e políticoinstitucional. Os grupos se utilizaram da visão do desenvolvimento que pretendiam e fizeram sugestóes de açóes. "Dos então nove eixos estratégicos apresentados, as microrregióes priorizaram duas açôes por eixo. Após os Núcleos Técnico e Dirigente fizeram nova sistematização e apresentaram em plenária para aprovação" (CODETER, 2014, p. 81).

$\mathrm{Na}$ sequência, o processo de construção do planejamento retornou para as microrregióes definirem prioridades de ação e de encaminhamento dos projetos. Novamente as proposiçóes foram sistematizadas em um quadro de eixos, programas e açóes, conforme as prioridades definidas, e que constam no Quadro 1, que segue.

Os temas apresentados no Quadro 1 perpassam a qualidade de vida das famílias rurais, o turismo rural, a inovação e diversificação das diversas matrizes produtivas, a formação e consolidação de agroindústrias, os processos associativistas, a consolidação das cadeias produtivas existentes, a sustentabilidade ambiental e a articulação dos agricultores nas mais diversas instâncias. 
Quadro 1 - Eixos, programas e açóes do Codeter Vale do Taquari

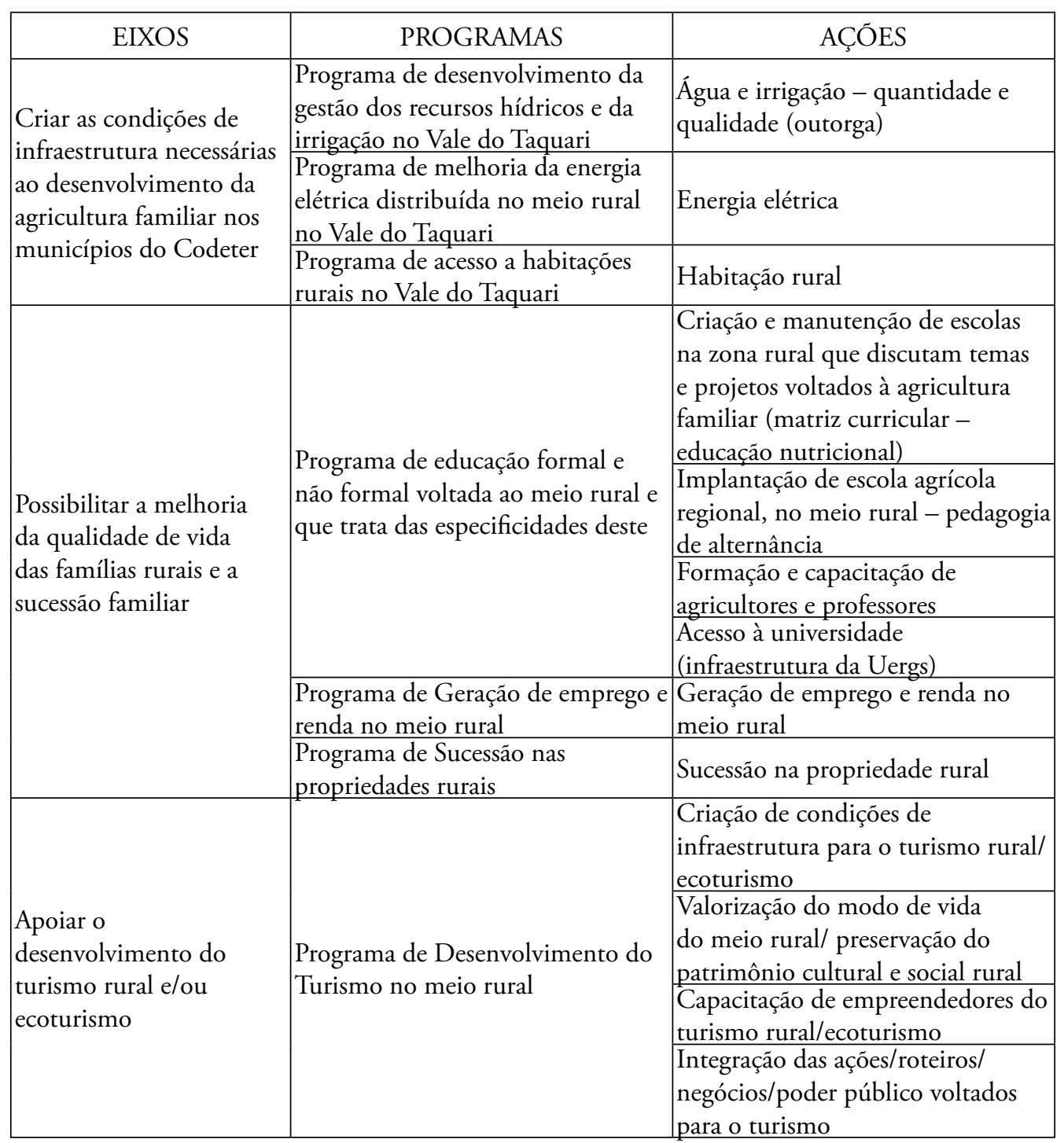




\begin{tabular}{|c|c|c|}
\hline EIXOS & PROGRAMAS & AÇÓEES \\
\hline \multirow{4}{*}{$\begin{array}{l}\text { Apoiar o } \\
\text { desenvolvimento, } \\
\text { inovação e diversificação } \\
\text { das matrizes produtivas } \\
\text { oriundas da agricultura } \\
\text { familiar }\end{array}$} & $\begin{array}{l}\text { Programa de qualificação da } \\
\text { assistência técnica voltada } \\
\text { à diversificação e inovação } \\
\text { tecnológica }\end{array}$ & $\begin{array}{l}\text { Assistência técnica voltada } \\
\text { à diversificação e inovação } \\
\text { tecnológica }\end{array}$ \\
\hline & $\begin{array}{l}\text { Programa de fomento para } \\
\text { diversificaçáo de culturas e criaçóes, } \\
\text { que agreguem valor à propriedade e } \\
\text { tenham mercado }\end{array}$ & $\begin{array}{l}\text { Diversificação de culturas e } \\
\text { criaçóes, que agreguem valor à } \\
\text { propriedade e tenham mercado } \\
\text { (ex. bovino de corte, piscicultura, } \\
\text { plantas não convencionais) }\end{array}$ \\
\hline & $\begin{array}{l}\text { Programa de fomento à produção } \\
\text { para atendimento da demanda para } \\
\text { a alimentação escolar }\end{array}$ & $\begin{array}{l}\text { Atendimento da demanda para a } \\
\text { alimentação escolar (logística) }\end{array}$ \\
\hline & $\begin{array}{l}\text { Programa de estruturaçáo para a } \\
\text { regionalizaçáo do abastecimento de } \\
\text { produtos oriundos da agricultura } \\
\text { familiar }\end{array}$ & $\begin{array}{l}\text { Regionalização do abastecimento } \\
\text { de produtos oriundos da } \\
\text { agricultura familiar }\end{array}$ \\
\hline \multirow{4}{*}{$\begin{array}{l}\text { Implantar e manter as } \\
\text { agroindústrias familiares }\end{array}$} & \multirow{4}{*}{$\begin{array}{l}\text { Programa de formação, } \\
\text { manutençáo e organizaçáo de } \\
\text { agroindústrias familiares e das } \\
\text { redes de cooperação e/ou formas } \\
\text { cooperativas para desenvolvimento } \\
\text { destas. }\end{array}$} & $\begin{array}{l}\text { Acesso às informaçóes, nivelamento } \\
\text { das legislaçóes estaduais e federal } \\
\text { e padronização da legislaçáo } \\
\text { municipal }\end{array}$ \\
\hline & & Produção/Acesso à matéria-prima \\
\hline & & $\begin{array}{l}\text { Organização/redes/formas } \\
\text { cooperativas }\end{array}$ \\
\hline & & $\begin{array}{l}\text { Comercialização/distribuição/ } \\
\text { abatedouro da produçáo }\end{array}$ \\
\hline \multirow{2}{*}{$\begin{array}{l}\text { Fomentar a formação } \\
\text { e a manutençáo do } \\
\text { associativismo e } \\
\text { cooperativismo }\end{array}$} & \multirow{2}{*}{$\begin{array}{l}\text { Programa de educação } \\
\text { cooperativista e de formação e } \\
\text { manutenção de associaçóes e } \\
\text { cooperativas }\end{array}$} & $\begin{array}{l}\text { Informação/formaçáo/educação } \\
\text { cooperativista }\end{array}$ \\
\hline & & $\begin{array}{l}\text { Formação e manutenção de } \\
\text { associaçôes/cooperativas }\end{array}$ \\
\hline \multirow{4}{*}{$\begin{array}{l}\text { Consolidar as cadeias } \\
\text { produtivas existentes }\end{array}$} & $\begin{array}{l}\text { Programa de desenvolvimento da } \\
\text { cadeia produtiva da Bovinocultura } \\
\text { de Leite }\end{array}$ & Bovinocultura de Leite \\
\hline & $\begin{array}{l}\text { Programa de desenvolvimento da } \\
\text { cadeia produtiva da Olericultura }\end{array}$ & Olericultura \\
\hline & $\begin{array}{l}\text { Programa de desenvolvimento da } \\
\text { cadeia produtiva de Gráos }\end{array}$ & Grãos \\
\hline & $\begin{array}{l}\text { Programa de desenvolvimento da } \\
\text { cadeia produtiva da Fruticultura }\end{array}$ & Fruticultura \\
\hline
\end{tabular}




\begin{tabular}{|c|c|c|}
\hline EIXOS & PROGRAMAS & AÇÓES \\
\hline \multirow{5}{*}{$\begin{array}{l}\text { Promover o } \\
\text { desenvolvimento a } \\
\text { partir da percepção } \\
\text { da sustentabilidade } \\
\text { ambiental }\end{array}$} & $\begin{array}{l}\text { Programas para tratamento, } \\
\text { redução e destinação dos resíduos } \\
\text { no meio rural }\end{array}$ & $\begin{array}{l}\text { Tratamento, redução e destinação } \\
\text { dos resíduos/dejetos orgânicos }\end{array}$ \\
\hline & \multirow{2}{*}{$\begin{array}{l}\text { Programa de transição } \\
\text { agroecológica no Vale do Taquari }\end{array}$} & $\begin{array}{l}\text { Produção mais limpa/redução de } \\
\text { uso de agrotóxicos }\end{array}$ \\
\hline & & Manejo/conservação de solos \\
\hline & $\begin{array}{l}\text { Programa de adequação das } \\
\text { propriedades e licenciamento } \\
\text { ambiental }\end{array}$ & $\begin{array}{l}\text { Adequação do sistema de } \\
\text { licenciamento ambiental }\end{array}$ \\
\hline & $\begin{array}{l}\text { Programa de acesso à mecanização } \\
\text { agrícola e tecnologias voltadas } \\
\text { à sustentabilidade ambiental, } \\
\text { econômica e social das } \\
\text { propriedades rurais }\end{array}$ & $\begin{array}{l}\text { Mecanização agrícola/tecnologias } \\
\text { voltadas para a sustentabilidade } \\
\text { ambiental }\end{array}$ \\
\hline \multirow{4}{*}{$\begin{array}{l}\text { Possibilitar a articulação } \\
\text { dos agricultores familiares } \\
\text { com as diversas instâncias }\end{array}$} & $\begin{array}{l}\text { Programa de fortalecimento e } \\
\text { qualificação da assistência técnica } \\
\text { rural }\end{array}$ & $\begin{array}{l}\text { Fortalecimento da assistência } \\
\text { técnica e extensão rural pública, } \\
\text { gratuita e focada na agricultura } \\
\text { familiar }\end{array}$ \\
\hline & \multirow{3}{*}{$\begin{array}{l}\text { Programa de capacitação, formação } \\
\text { de líderes e articulação dos atores } \\
\text { locais e regionais, em prol do } \\
\text { desenvolvimento rural }\end{array}$} & $\begin{array}{l}\text { Articulação dos atores nas cadeias } \\
\text { produtivas (participação mais ativa } \\
\text { dos agricultores, STRs e outros) }\end{array}$ \\
\hline & & $\begin{array}{l}\text { Capacitação de conselhos e } \\
\text { conselheiros }\end{array}$ \\
\hline & & $\begin{array}{l}\text { Articulaçáo para atuaçáo nos } \\
\text { programas e políticas destinados } \\
\text { aos agricultores }\end{array}$ \\
\hline
\end{tabular}

Fonte: Adaptado de Codeter (2014, p. 84-85).

A partir da aprovação da plenária, considerando os temas identificados e prioritários para o Codeter Vale do Taquari, foram definidos cinco grupos de trabalho temáticos: leite, água, energia, diversificação e dejetos orgânicos. Também foi identificado o tema da qualificação e/ou capacitação, considerado transversal a todos os grupos de trabalho. A incumbência principal dos grupos é levar adiante a formataçáo de projetos para a agricultura familiar do Vale do Taquari.

Percebe-se, pelo cronograma identificado no Pré-Plano, que, desde dezembro de 2011, quando o processo iniciou, até fins de 2013, quando da disponibilidade de informaçóes do Pré-Plano, foram realizadas oito plenárias gerais do Colegiado, nove reunióes do Núcleo Dirigente e Técnico, quatro reunióes dos grupos de trabalho formados, além dos encontros municipais e microrregionais já citados.

Como o Codeter é formado no ano de 2011 e durante o período de 2011 a 2013 foi construído o Pré-plano Territorial do Vale do Taquari, a tarefa dos núcleos dirigente e técnico e dos grupos de trabalho é consolidar o Colegiado como o articulador do desenvolvimento rural, da agricultura familiar na região. 


\section{CONSIDERAÇÓES FINAIS}

O Codeter Vale do Taquari é recente e até o presente momento apresenta uma perspectiva sustentável do desenvolvimento rural a partir da agricultura familiar.

Historicamente a regiáo foi e é formada por pequenas propriedades, com uso da máo de obra familiar e culturas diversificadas. Esse aspecto reforça a percepçáo de que os agricultores familiares definiram se unir via Codeter para, num primeiro momento, encaminhar projetos ao Ministério do Desenvolvimento Agrário. Ainda, a dimensão histórica reforça a perspectiva associativa regional, enfatizada na formação dos Codeters enquanto Colegiado de gestâo participativa.

É por óbvio que o Codeter está atendendo a um regramento do próprio MDA, no entanto são enfáticos na necessidade de participação e na paridade dos atores que são membros do colegiado.

Ainda o Colegiado percebe as diversas escalas e necessidades de articulá-las. Mesmo neste pré-plano as escalas foram dimensionadas em municípios, microrregiáo e região, no entanto demonstram estar articuladas de forma linear. $\mathrm{Na}$ dimensão territorial, mesmo que náo percebido claramente pelos atores, houve construção de microrregiōes, identificação de necessidades e temas locais, microrregionais e regionais, ou seja, a construçáo de uma possível identidade regional para o tema do desenvolvimento rural.

Reforçam as perspectivas bottom-up tanto a ação do MDA e SDT como a própria formação dos Codeters, na percepção da participação social e atuação regional, como também do Codeter Vale do Taquari, que busca a participação dos mais diversos atores, nas mais variadas escalas, articulando-as no contexto do território.

Em se tratando da multidimensionalidade do desenvolvimento rural, foram discutidos e levantados temas vinculados aos aspectos econômicos, sociais, ambientais e políticoinstitucionais, nas diversas escalas e, mais, com o questionamento de qual desenvolvimento tem-se e, posteriormente, qual desenvolvimento desejam os atores envolvidos.

Por fim, a perspectiva de um Codeter no Vale do Taquari consolidado, o que por ora está em construção, pode sim contribuir e ser uma instância de articulação dos agricultores familiares para o desenvolvimento rural dessa região.

\section{REFERÊNCIAS}

ABRAMOVAY, R. et al. Representatividade e inovação na governança dos processos participativos: o caso das organizaçóes brasileiras de agricultores familiares. Sociologias, Porto Alegre, ano 12, n. 24, p. 268-306, maio/ago. 2010.

ALVES, A. J. A “revisão da bibliografia” em teses e dissertações: meus tipos inesquecíveis. Cadernos de Pesquisa, São Paulo, n. 81, maio 1992, p. 53-60.

AVRITZER, L. Sociedade civil e participação no Brasil democrático. In: (org.).

Experiências nacionais de participaçáo social. São Paulo: Cortez, 2009. 
BAQUERO, Marcello. et al. Reflexões sobre a pesquisa nas ciências humanas. Barbarói. Santa Cruz do Sul, n. 2, p. 17-32, mar./1995.

BUAINAIN, A. M.; ROMEIRO, A. R.; GUANZIROLI, C. Agricultura familiar e o novo mundo rural. Sociologias, Porto Alegre, ano 5, n. 10, p.312-347, jul./dez. 2003.

CODETER VALE DO TAQUARI. Pré-Plano Territorial de Desenvolvimento Rural do Vale do Taquari, 2014, no prelo.

CONTERATO, M. A.; SCHNEIDER, S.; WAQUIL, P. D. Estilos de agricultura: uma perspectiva para a análise da diversidade da agricultura familiar. Ensaios FEE, Porto Alegre, v. 31, n. 1, p. 149-186, 2010.

DAGNINO, E. ¿Sociedade civil, participação e cidadania: de que estamos falando? In: MATO, D. (coord.). Políticas de ciudadanía y sociedade civil en tempos de globalización. Caracas: FACES, Universidad Central de Venezuela, p. 95-110, 2004.

DAGNINO, E.; OLVERA, A. J.; PANFICHI, A. Para uma outra leitura da disputa pela construção democrática na América Latina. In: . (orgs.). A disputa pela

construçáo democrática na América Latina. São Paulo: Paz e Terra; Campinas:

Unicamp, p.13-92, 2006.

DELGADO, N. G.; LEITE, S. P. Políticas de Desenvolvimento Territorial no Meio Rural Brasileiro: Novas Institucionalidades e Protagonismo dos Atores. DADOS - Revista de

Ciências Sociais, Rio de Janeiro, v. 54, n. 2, p. 431 - 473, 2011.

DEPONTI, C. M. O processo de desenvolvimento rural à luz da perspectiva orientada ao ator: o caso da extensão rural brasileira. In: Alasru - VII Congresso Latinoamericano de Sociologia Rural, 2006, Quito. Asociacion Latinoamericana de Sociologia Rural, 2006.

DURANTE, M. O.; SANDES, W. F. Avanços na democracia brasileira: a participação da sociedade civil na Conferência Nacional de Segurança Pública, Revista Brasileira de Segurança Pública, Ano 3, Edição 5, Ago/Set 2009.

DURIGUETTO, M. L. Sociedade civil e democracia: um debate necessário. Libertas, Juiz de Fora, v. 8, n. 2, p. 83 - 94, jul-dez / 2008.

ELLIS, F.; BIGGS, S. Evolvingthemes in rural development 1950s-2000s.

DevelopmentPolicyReview, 2001, 19 (4): 437-448.

ETGES, V. E. Desenvolvimento regional sustentável: o território como paradigma. REDES, Santa Cruz do Sul, v. 10, n. 3, p. 47-55, set/dez. 2005.

FETAG; UNIVATES. Dinâmica populacional e a sucessão da agricultura familiar no Vale do Taquari. Lajeado: Univates, 2005. 
FLORES, M. A identidade cultural do território como base de estratégias de desenvolvimento: uma visão do estado da arte. 2006. Disponível em: <http://www. fidamerica.cl/admin/docdescargas/centrodoc/centrodoc_236.pdf>. Acesso em: 20 mar. 2014.

FIORI, J. L. Globalização, hegemonia e império. In: TAVARES, M. da C.; FIORI, J. L. (org.). Poder e dinheiro: uma economia política da globalização. Petrópolis/Rio de Janeiro: Vozes, p. 87-150, 1997.

FOLEY, M. W.; EDWARDS, B. Perspective: Editors' Introduction Beyond Tocqueville: Civil Society and Social Capital in Comparative. American Behavioral Scientist, 42, 5, 1998.

FRANCO, R. Um novo contrato social? Sociedade civil, participação e a experiência do Conselho de Desenvolvimento Econômico e Social. Dissertação de Mestrado. Rio de Janeiro: PUC-RJ, mar. 2007.

FREITAS, A. F. de; FREITAS, A. F. de; DIAS, M. M. Gestão Social e Políticas Públicas de Desenvolvimento Territorial. APGS, Viçosa, v. 4, n. 1, p. 76-100, jan./mar. 2012.

GIL, A. C. Métodos e técnicas de pesquisa social. São Paulo: Atlas, 1999.

GRANOVETTER, M. Economic Action and Social Structure: the problem of embeddedness. American Journal of Sociology, v. 91, v. 3, nov. 1985, p. 481-510.

HEROD, A. Scale: the local and the global. In: HOLLOWAY, S. L.; RICE, S. P; VALENTINE, G. (eds.). Key concepts in geography. London: Sage, 2003.

HOUTZAGER, P.; LAVALLE, A. G.; ACHARYA, A. Atores da sociedade civil e atores políticos - participação nas novas políticas democráticas em São Paulo. In: AVRITZER, L. Participaçáo em Sáo Paulo. São Paulo: UNESP, 2004 (no prelo).

KAGEYAMA, A. Desenvolvimento rural: conceito e medida. Cadernos de Ciência \& Tecnologia, Brasília, v. 21, n. 3, p. 379-408, set./dez. 2004.

LATOUR, B. Reagregando o social: uma introdução à teoria do ator-rede. Salvador: DUFBA - Edusc, 2012.

LAVALLE, A. G. Sem pena nem glória: o debate sobre a sociedade civil nos anos 1990. Novos Estudos. n. 66. jul./2003.

. O estatuto político da sociedade civil: evidências da Cidade do México e de São Paulo. Textos para Discussáo - CEPAL/IPEA, n. 28, 2011.

LONG, N.; PLOEG, J. D. Heterogeneidade, ator e estrutura: para a reconstituição do conceito de estrutura. In: SCHNEIDER; S.; GAZOLLA, M. (Orgs.). Os atores do 
Desenvolvimento Rural: perspectivas teóricas e práticas sociais. Porto Alegre: Editora da UFRGS, 2011. p. 21-48.

MDA - Ministério do Desenvolvimento Agrário. Disponível em: <http://www.mda. gov.br>. Acesso em: 21 jan. 2015.

MEDEIROS, M. A trajetória do WelfareState no Brasil: papel redistributivo das políticas sociais dos anos 1930 aos anos 1990. Texto para Discussáo n. 852. Brasília, dez. 2001. Disponível em: <http://repositorio.ipea.gov.br/handle/11058/2058>. Acesso em: 22 ago. 2015.

NAVARRO, Z. Desenvolvimento rural no Brasil: os limites do passado e os caminhos do futuro. Estudos Avançados, v.15, n. 43, p.83-100, 2001.

PEREIRA, J. D.; SILVA, S. S. de S.; PATRIOTA, L. M. Políticas sociais no contexto neoliberal: focalização e desmonte dos direitos. Qualit@s - Revista Eletrônica. ed. Especial, v. 5, 2006.

PUTNAM, R. D. Comunidade e Democracia: a experiência da Itália moderna. Rio de Janeiro: Editora da Fundação Getúlio Vargas, 1996.

RAMOS, L. C. S. A sociedade civil em tempos de globalização: uma perspectiva neogramsciana. Dissertação de Mestrado. Rio de Janeiro: PUC, 2005.

SABOURIN, E. Teoria da Reciprocidade e socioantropologia do desenvolvimento. Sociologias, Porto Alegre, ano 13, n. 27, maio/ago. 2011, p. 24-51.

SANTOS, A. R. dos. Metodologia científica: a construção do conhecimento. 7. ed. Rio de Janeiro: Lamparina, 2007.

SANTOS, M. A natureza do espaço - técnico e tempo, razão e emoção. São Paulo: Hucitec, 1996.

SARDAN, J. O. Anthropologie et dèveloppement - essai em sócio - anthropologie. Du changement social. Karthala, 1995.

SCHERER-WARREN, I.; LÜCHMANN, L. H. H. Situando o debate sobre movimentos sociais e sociedade civil no Brasil - Introdução. Revista Política e Sociedade, n. 5, p.1335, outubro 2004 .

SCHNEIDER, S. A abordagem territorial do desenvolvimento rural e suas articulaçóes externas. Sociologias, Porto Alegre, ano 6, n. 11, p. 88-125, jan./jun. 2004.

- Situando o desenvolvimento rural no Brasil: o contexto e as questóes em debate.

Revista de Economia Política, v. 30, n. 3, p. 511-531, julho/set. 2010. 
SCOTT, J. C. Exploração normal, resistência normal. Revista Brasileira de Ciência Política, n. 5. Brasília, jan./jun. 2011.

VERGARA, S. C. Métodos de pesquisa em administraçáo. São Paulo: Atlas, 2005.

VILPOUX, O. F.; LAURINO, J.; CAMPEÁO, P. Papel dos Colegiados no desenvolvimento de uma política de integração territorial: exemplo dos Territórios Rurais do Mato Grosso do Sul. Desenvolvimento em Questáo. Unijuí, ano 12, n. 28, out./dez. 2014. 